\title{
CERAMICAS CAMPANIFORMES DE LA PROVINCIA DE CUENCA
}

\author{
POR \\ JESUS M. ${ }^{a}$ MARTINEZ GONZALEZ
}

\begin{abstract}
RESUMEN Se estudian en este artículo un grupo de cerámicas inéditas de los yacimientos del cerro del Otero en Caracenilla y del Castillo en Huete, junto a otras dos piezas de Buendia, Villarrubio, yacimientos todos ellos de la provincia de Cuenca.

Lo significativo de este conjunto material es su posición intermedia, tanto cronológica como cultural, entre las variedades más típicas del campaniforme y las del regional "Grupo Dornajos", con lo que esto supone de ligazón para el establecimiento de la secuencia campaniforme de la zona.
\end{abstract}

ABSTRACT This article concerns a group of unpublished ceramics from the sites of Cerro de Otero (Caracenilla), Castillo de Huete, Buendía, and Villarrubio, all in the province of Cuenca. The significant feature of this group is its chronologically and culturally intermediate position between the classic Beaker pottery types and the ceramics of the Los Dornajos group in Cuenca. This has important implications for establishing the Beaker sequence in this region.

Palabras clave: Cerámica campaniforme. Grupo Dornajos. Cuenca. Calcolítico. Bronce antiguo.

Hasta fechas recientes, el único elemento cerámico adscrito al fenómeno campaniforme en la provincia de Cuenca era un fragmento de cuenco encontrado en las proximidades de la localidad de Buendía (Valiente, 1974). Este, unido a las piezas metálicas del "Cerro de la Muela» en Carrascosa del Campo, "Valeria" y "Pico de la Muela" en Valera de Abajo (Osuna, 1974) constituían los restos materiales que documentaban la presencia de este horizonte cultural en la zona.

Posteriormente, en las excavaciones realizadas en los poblados de «Los Dornajos" en La Hinojosa (Galán y Poyato, 1978-79 y Galán y Fernández Vega, 1982-83) y "Pico de la Muela" en Valera de Abajo (Valiente, 1981) se obtuvieron nuevos materiales que, junto a otros recogidos en rellenos medievales y prospecciones de superficie como los de las morrotas de "Los Cotos» y «El Gurugú» en Cervera del Llano (Chapa.et alii., 1979), el "Cerro Pelao" de Alcohujate, Villaescusa de Haro, el "Castillo» de Huete (Martínez Navarrete, 1985), "Villas Viejas" en Saelices (Poyato y Galán, 1985) o «El Castillow de la Puebla de Almenara (Coll et alii., 1986) ponían de manifiesto la existencia en esta parte de la Submeseta Sur de unas variedades cerámicas muy originales cuyas peculiaridades y personalidad propia dentro de las cerámicas incisas de la Edad del Bronce de la Meseta eran señaladas por la mayor parte de los autores referenciados. 
Estas variedades, denominadas "grupo Dornajos» (Poyato y Galán, 1985) (1) están caracterizadas por unos recipientes ampliamente decorados, tanto en su interior como en el exterior, con unos repertorios que si bien presentan grandes afinidades temáticas con los más clásicos registros campaniforme incisos del tipo Ciempozuelos, muestran, sin embargo, unas acusadas diferencias con los mismos en cuanto a su tratamiento, disposición espacial y desarrollos.

Con todo, su definición cultural y cronológica se veía dificultada por la falta de elementos intermedios que permitieran observar el tipo y el grado de las relaciones existentes entre estas cerámicas y las campaniformes, y por la ausencia de una caracterización suficiente del propio fenómeno campaniforme en el área.

Las actuales excavaciones emprendidas en "El Castillo» de Huete y las prospecciones de superficie realizadas por D. Santiago Serrano en el «Cerro del Otero* en Caracenilla, yacimiento situado a unos $12 \mathrm{Kms}$. del primero, proporcionaron nuevos datos para abordar estas cuestiones, ya que en todas las cerámicas con decoración recuperadas se definian claramente algunos elementos distintivos que las diferenciaban tanto de las del «grupo Dornajos" como de las típicas campaniformes incisas.

En este trabajo, se analizan estos materiales inéditos y dos fragmentos más existentes en el Museo Provincial de Cuenca; el referido cuenco de Buendía y el borde de un vaso de Villarrubio.

Lo reducido de su número y la carencia de un contexto arqueológico más concreto, imponen unas severas limitaciones a su interpretación cultural y cronológica, aspectos sobre los que, no obstante, creemos que es posible hacer algunas sugerencias que se verán confirmadas y ampliadas con la obtención de futuros materiales en otras excavaciones y yacimientos de la región.

\section{EL ENTORNO FISICO}

Los cuatro yacimientos cuyas cerámicas se estudian, Buendia, Huete, Caracenilla y Villarrubio, se sitúan dentro del paisaje característico de una comarca interior de la Meseta bien diferenciada geográficamente: La Alcarria (Fig. 1).

Esta región, que ocupa en la provincia de Cuenca un amplio espacio de su zona Noroeste y Oeste, está constituida geológicamente, por formaciones sedimentarias terciarias (arcillas, calizas, yesos, margas, etc.). Materiales fácilmente erosionables que han propiciado la formación de un relieve marcadamente irregular jalonado de cerros testigos u oteros, de los cuales el Castillo de Huete y el de Otero de Caracenilla pueden ser unos buenos ejemplos.

Los parajes de los que proceden estos materiales cuentan con buenos recursos hídricos. Así, el pueblo de Buendia se encuentra en las inmediaciones del Guadiela, afluente del Tajo, de cuyo curso alto tampoco se halla muy alejado. Huete y Caracenilla dominan el valle del Mayor, afluente del Guadiela y están muy próximos a las cabeceras de dos importantes afluentes del Guadiana, el Záncara y el Cigüela, especialmente del segundo, en cuya cuenca se sitúa Villarrubio. Sin olvidar la cercanía de todos ellos a un significativo río de la vertiente mediterránea como el Júcar y su relativa proximidad a otro importante afluente del Ebro, el Jalón.

El actual paisaje vegetal está compuesto por pequeñas manchas de bosque residual y, principalmente, por matorral de tipo xerófilo (tomillo, esparto, aliagas, etc.), buen reflejo de la degradación constante de las especies forestales que, como el encinar o carrascal, pudieron constituir junto a otras formaciones de soto próximas a los ríos (chopos, olmos, sauces, etc.) la principal vegetación de la zona en el momento subboreal al que corresponden estos asentamientos.

(1) Para estas autoras, la denominación «Grupo Dornajos», dada a tales variedades cerámicas, se establece no sólo en función de que es en el yacimiento de este mismo nombre donde se da un porcentaje más alto de estas especies, sino también porque sus características «tanto formales como los contextos en que se encuentran, parecen indicar que se trata de algo muy característico de esta región y, tal vez, con un significado particulan (Poyato y Galán, 1985). 


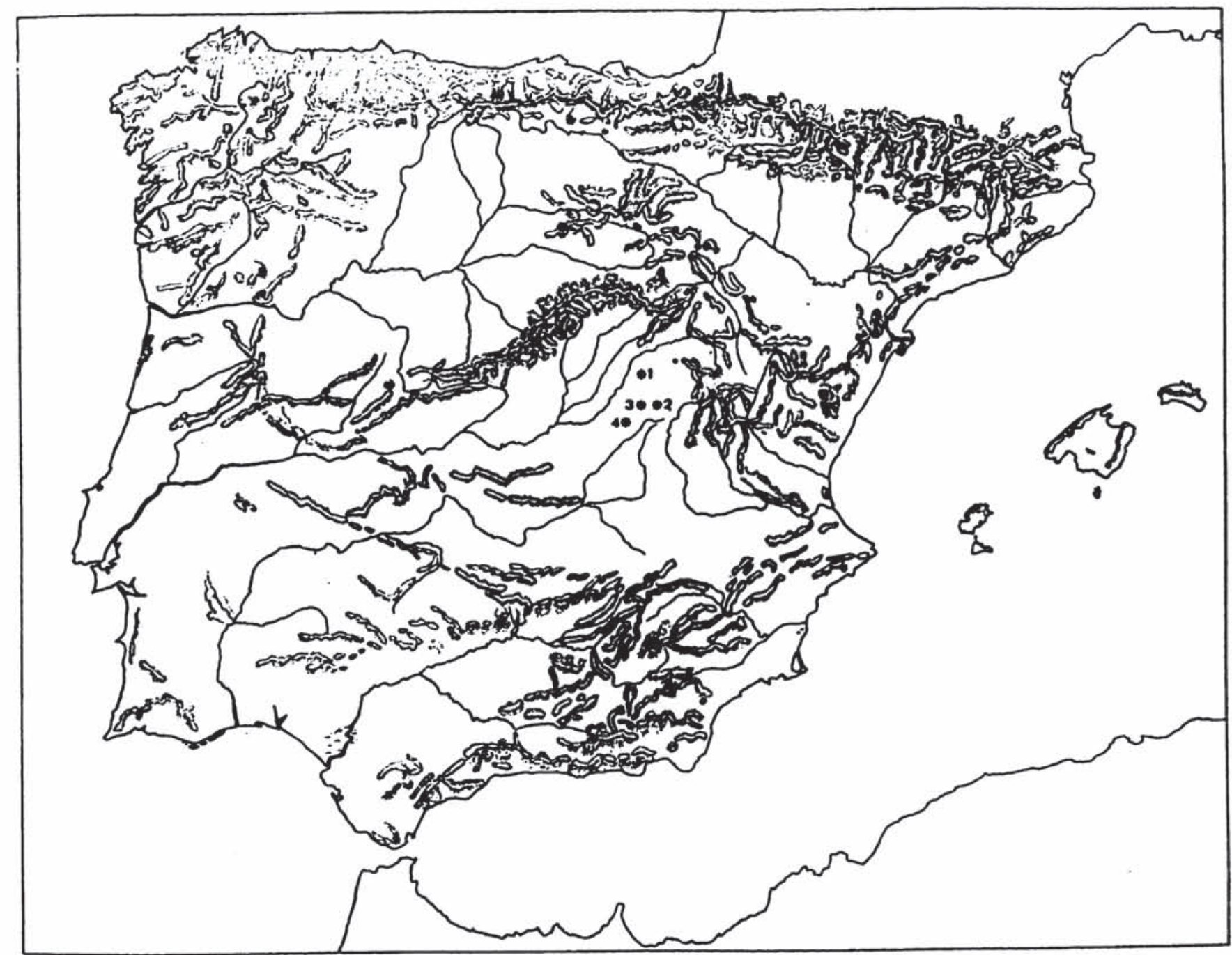

FIG. 1.-Situación de los yacimientos. 1) Buendia; 2)Caracenilla; 3) Huete, y 4) Villarrubio.

Por lo que a los recursos económicos se refiere, esta comarca, muy pobre en minerales, prácticamente inexistentes, debió permitir únicamente unas actividades poco intensivas de tipo primario como la ganadería, la agricultura y, quizá, en algunos casos, la horticultura (Poyato y Galán, 1985). A este respecto, parece significativo señalar la presencia en las inmediaciones de los yacimientos de varias cañadas y veredas con topónimos como «vereda de Soria» en Huete.

En cuanto a la exacta ubicación de los yacimientos a los que pertenecen las piezas estudiadas debemos advertir que, a diferencia, de las de Huete y Caracenilla para las que se posee una localización muy precisa y completa, de Villarrubio y Buendia únicamente se conoce a grandes rasgos su situación (2).

El "Cerro del Otero" en Caracenilla, de 973 metros s.n.m. se sitúa entre los $40^{\circ} 09^{\prime}$ y $40^{\circ} 10^{\prime}$ de Latitud y los $1^{\circ} 06^{\prime}$ y $1^{\circ} 07^{\prime}$ de Longitud, según la hoja n.9 608 , Huete, del Mapa Topográfico

(2) El fragmento de Buendía se recogió en las cercanías de este pueblo, «en las proximidades a la orilla del pantano» (Valiente, 1974: 133). El correspondiente a Villarrubio, formaba parte del depósito de materiales entregados al Museo Provincial de Cuenca por la Dra. M.* I. Martínez Navarrete y D. Juan Martínez, procedentes, según comunicación escrita de la primera, de wuna prospección de superficie llevada a cabo en una zona llana, ligeramente ascendente, de un amplio valle situado en paralelo con la carretera antes de llegar al pueblo de Villarrubiow. 
Nacional a escala 1:50.000. Como su nombre indica, se trata de un cerro testigo desde el que se posee un amplio dominio visual y estratégico tanto de una gran parte del valle del río Mayor como de sus afluentes.

La cima es ligeramente amesetada, aunque de reducidas dimensiones. Sus laderas Sur, Este y Oeste están fuertemente erosionadas, presentando una acusada pendiente. La Norte, por el contrario, muestra un perfil más suave, escalonado, quizá producto de una continuada actividad humana (construcciones, cultivos, etc.). En la actualidad, esta ladera se encuentra aterrazada para la plantación de pinos con lo que se ha destruido una buena parte de las estratigrafías arqueológicas existentes.

En esta ladera se recogieron la práctica totalidad de las cerámicas estudiadas aquí, así como otras de etapas más avanzadas de la Edad del Bronce (Cogotas I), Primera Edad del Hierro (cerámica pintada) y celtibéricos. Estos últimos, constituyen los materiales más modernos encontrados, lo que permite suponer que la ocupación, más o menos intensiva del cerro debió concluir en momentos cercanos a la romanización. En este mismo sentido, apuntarían los despoblados existentes en la parte noroeste del cerro, ya en la zona más próxima al fondo del valle.

El cerro de "El Castillow en Huete, de 926 metros s.n.m. se sitúa entre los $40^{\circ} 08^{\prime} 56^{\prime \prime}$ de Latitud y los $0^{\circ} 59^{\prime} 49^{\prime \prime}$ de Longitud según la hoja n. ${ }^{2} 608$, Huete, del Mapa Topográfico Nacional a escala 1:50.000. Como el Otero de Caracenilla, posee unas laderas muy escarpadas, especialmente las Norte, Este y Oeste, siendo, en este caso, la Sur, la que tiene una menor pendiente y por donde actualmente se accede a él. Geológicamente, está constituido por areniscas, margas y tobas calizas principalmente. Al Este discurre el río Cauda o Borbotón. La ciudad de Huete se establece en sus laderas Este y Sureste.

Los restos arqueológicos encontrados hasta ahora, tanto en superficie como en las excavaciones realizadas, ponen de manifiesto unos asentamientos humanos que arrancando de momentos cercanos al segundo milenio antes de Cristo alcanzan fechas situadas a finales del siglo XIV o principios del XV (Santos García et alii., 1985 y Jiménez Pérez, 1985). Entre los correspondientes a épocas prehistóricas, destacan los del Bronce Final y Primer Hierro (Martínez González y Martínez Navarrete, 1985).

\section{ANALISIS DE LOS MATERIALES}

El conjunto cerámico estudiado está compuesto por 47 fragmentos, de los cuales, 38 son de Caracenilla, 7 de Huete y 1, en cada caso, de Buendía y Villarrubio. Predominan los correspondientes a paredes (23 en Caracenilla y 4 en Huete) y a bordes (14 en Caracenilla, 3 en Huete y el 1 en Buendía y Villarrubio), perteneciendo únicamente uno a un fondo (Caracenilla). No se registran asas, mamelones ni cualquier otro tipo de elemento de presión.

Esta muestra, fuertemente selectiva, tiene como principal elemento distintivo las decoraciones.

\section{Caracteristicas generales (3)}

El tamaño de los fragmentos oscila entre los $125 \mathrm{~mm}$. y los $16 \mathrm{~mm}$. de longitud máxima, siendo, no obstante, los valores situados entre los $20 \mathrm{~mm}$. y los $50 \mathrm{~mm}$. los más frecuentes en los cuatro yacimientos. Sus grosores máximos se encuentran comprendidos entre los $13 \mathrm{~mm}$. de la pieza número 1 de Caracenilla y los $5 \mathrm{~mm}$. de la número 60, igualmente de Caracenilla, aunque son los comprendidos entre 5 y $10 \mathrm{~mm}$. los más representados en estas cerámicas (Fig. 2).

El tipo de cocción más empleado en este conjunto ha sido la reducción, estando también presente, aunque en mucho menor grado, la oxidación (tres casos en Caracenilla y uno en Huete y Villarrubio) y la alternante, observada en cinco fragmentos de Caracenilla y uno de Huete. El nervio de cocción se registra en tres fragmentos de Caracenilla.

(3) Para este análisis, se ha empleado, simplificado, el procedimiento de M.* D. Asquerino para materiales sin estratigrafia (Asquerino, 1978). 
Caracenilla

Huete

\begin{tabular}{|c|c|c|c|c|c|c|c|c|c|c|c|c|c|c|c|c|c|c|c|c|c|c|c|c|c|c|c|c|c|c|c|c|c|c|c|c|c|}
\hline \multicolumn{3}{|c|}{ Nimero } & 1 & 2 & 3 & 5 & 6 & 7 & 8 & $\pi$ & & 13 & & 10. & $\mathbf{6}$ & & & & & & & & & & 313 & 203 & 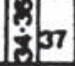 & & 1010 & 2010 & & 5000 & & 2 & 3 & 4 & 5 \\
\hline \multirow{3}{*}{ 这 } & \multicolumn{2}{|c|}{ Borde } & & & & & & & e & 0 & & & & & & & & & & e1 & e & e잉 & to & a & e & & 10 & & E & 50 & e & 90 & 0 & & - & & \\
\hline & \multirow{2}{*}{\multicolumn{2}{|c|}{$\begin{array}{l}\text { Pared } \\
\text { Fondo }\end{array}$}} & I & 0 & e & 0 & 0 & 0 & & & 0 & e & 0 & e. & 인 & 이 & $E$ & 2) & 0 & & e & & & & 의 & 이 & 0 & & 0 & & & & & 10 & & $\bullet$ & $\bullet$ \\
\hline & & & & & & & & & & & & & & & & & 0 & & & & & & & & 7 & $\square$ & $\square$ & & $\square$ & & & & $\square$ & 7 & & & \\
\hline \multirow{4}{*}{$\begin{array}{l} \\
\\
\\
\end{array}$} & \multicolumn{2}{|c|}{ Reducción } & & e & & 0 & & 0 & & 1 & 0 & 0 & e) & 0 & & 이 & & & e & e & 0 & & 10 & 8 & Q & 10 & 르 & & 0 & 10 & 10 & 00 & 0 & 린 & & & 0 \\
\hline & \multirow{2}{*}{\multicolumn{2}{|c|}{$\begin{array}{l}\text { Oxdación } \\
\text { N. de C. }\end{array}$}} & & & & & 0 & & 0 & & & & & & & & 잉 & & & & & & & & & & & & & & & & & & - & & \\
\hline & & & 5 & & & & & & & & & & & & & & Q & 9 & f & & & & & & & & & & & 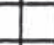 & 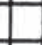 & $F$ & - & 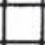 & & 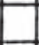 & 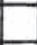 \\
\hline & \multicolumn{2}{|c|}{ Alternante } & & & e & & & & & & & & & & 아 & & & & & & & 0 & & & 은 & & & e & & & & & $\ldots$ & 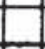 & & - & \\
\hline & & Garzo & & & & 10 & & & & & & & & 라 & & & & & & & & & & & & & & & & & & 일 & 7 & 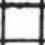 & & & \\
\hline & & Calka & I & e & 을 & & 0 & e & 을 & 을 & e & e & 0 & & e & e & 01 & 인 & 6 & 0 & 9 & 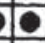 & 10 & 10 & 0 & e & 90 & e & ec & 90 & 0 & 90 & 0 & e & - & & 을 \\
\hline & 8 & Mica & & & & & & & & & & & & & & & & & & & & & & & & & & 7 & $\square$ & 1 & $\square$ & & $\square$ & $\square$ & & - & \\
\hline & 뜯 & Vegetal & & & & & & & & & & & & & & & & & & & & & & & & & & & & & & & & 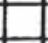 & & & \\
\hline 5 & & Otros & & & & & & & & & & & & & & & & & & & & & & & & & & & & & & & ] & 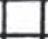 & & & \\
\hline द & & (?) & & & & & & & & & & & & & & & & & & & & & & & & & & & & & & & & & & & \\
\hline 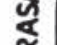 & & M.F. & & & 0 & & 0 & 0 & 0 & 0 & e & & & & & 임 & & $t$ & 90 & e & 0 & 10 & 10 & e) & & e & & 0 & e & 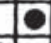 & 0 & & 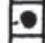 & - & & - & \\
\hline 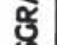 & 온 & Fino & e & 을 & & 0 & & & & & & 으 & 0 & 이 & 임 & & 00 & 2 & & & & & & & 0 & & 00 & & 9 & & & 00 & 7 & 1 & 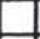 & & - \\
\hline 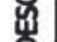 & $\$$ & Mecto & & & & & & & & & & & & & & & & & & & & & & & & & & & & & & & & & - & & \\
\hline & $\frac{3}{8}$ & Grueso & & & & & & & & & & & & & & & & & & & & & & & & & & & & & & L & & & & & \\
\hline & & M.C. & & & & & & & & & & & & & & & & & & & & & & & & & & & & & & & & & & & \\
\hline & Bru & ida & & e & & & & อ & & e & Q & & & & & e. & & & & 1 & & e & & 16 & & & ef & & Q12 & 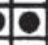 & & 우의 & e & & & 의 & 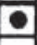 \\
\hline 畜 & As. & Fina & & & & 0 & 2 & & 을 & & & & 임 & e) & 이 & & 90 & 9 & 2 & & 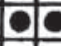 & & & a & 인 & 0 & 일 & ef & & & 인 & & & - & & & \\
\hline & Als: & ada & 을 & & 은 & & & & & & & 인 & & & & & & & 을 & & & & 2 & & e & & & & & & & & & & - & & \\
\hline$\underset{\hbar}{\mathscr{K}}$ & TosC & & & & & & & & & & & & & & & & & & & & & & & & & & & & & & & & & & & & \\
\hline$\underline{E}$ & Eros & sonada & & & & & & & & & & & & & & & & & & & & & & & & & & & & & & & & & & & \\
\hline & 5 & Redo. & & & & & & & 9 & & & & & & & & & & & & 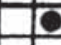 & & Q & ㅇ & 0 & & & & E & 20 & & 잉 & 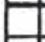 & & & & \\
\hline & 8 & Aptan. & & & & & & & & & & & & & & & & & & & 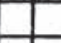 & $\theta$ & & & 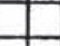 & & 이 & & & & 인 & 0 & - & & & & \\
\hline & 요 & Apunt. & & & & & & & & 을 & & & & & & & & & & a & & & & & & & & & & & & & & & 라 & & \\
\hline & 8 & Salente & & & & & & & 우 & 으 & & & & & & & & & & e & 0 & & & & 0 & & & & & - & e & & e & & 0 & & \\
\hline & 岃 & Recto & & & & & & & & & & & & & & & & & & & & & & & & & & & & & & & & & & & \\
\hline & & Entran. & & & & & & & & & & & & & & & & & & & & & & & & & & & e & & & & & & & & \\
\hline 岁 & & (?) & & & & & & & & 으 & & & & & & & & & & & & & ㅇ. & 인 & & & & & & - & & & & & & & \\
\hline 8 & & \begin{tabular}{|l|l|}
$5 \cdot 10$ \\
\end{tabular} & & & & & & & & & & & & & & & & & & & & & & & & & & & & & e) & & & & & & \\
\hline ఉ & 8 & $10-15$ & & & & & & & 인 & & & & & & & & & & & e & 은 & 의 & & & 0 & & 0 & & & & & $\bullet$ & L & & & & \\
\hline & 点 & $15-20$ & & & & & & & & & & & & & & & & & & & & & & & & & & & & & & $\bullet$ & e & & - & & \\
\hline & 安 & 20.25 & & & & & & & & & & & & & & & & & & & & & & & & & & & I & & & & & & & 1 & \\
\hline & & +25 & & & & & & & & & & & & & & & & & & & & & & & & & & & & $\square$ & & & 1 & & & 7 & 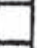 \\
\hline & hos: & & & 0 & $\overline{8}$ & 아 & ? & 9 & & 5 & $\bar{c}$ & 8 & $\underline{\underline{c}}$ & $\theta$ & 9 & of & 90 & 7 & 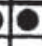 & 잉 & 90 & 을 & & 2 & 象 & 9 & e & 0 & 을 & 0 & - & 0 & 잉 & 0 & - & & - \\
\hline$z$ & Exck: & & & & & & & & & & & & & & & & & & & & & & & & & & $\square$ & & & & & & & & & & \\
\hline पू & mpr & resa & & ㅇ & 을 & & V & 의 & & 으 & 아 & 아 & 으 & & 9 & 의 & & & & 0 & 은 & & & & & & 아 & 단 & & & & & & & & & \\
\hline 8 & Bog & ulque & & & & & & & & & & & & & & & & & & & & & & & & & & & & & & & & & & & \\
\hline 8 & Relle & & & & & & & & & & & & & & & & & & & & & & & & & & & & & & & & & & & & \\
\hline 8 & Punt & tillacta & & & & & & & 의 & & & & & & & & & & & & & & & & & & & & & & & $\theta$ & & & & & \\
\hline 留 & Lons & 7. máx. & & & สำ & 8 & 5 & civ & ભ્ & $\mp$ & (2) & 8 & 5) & $2:=$ & $=$ & 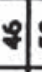 & 89 & & 5 & 8 & 88 & gx & $\%$ & 8 & $2=$ & 81 & เి 8 & 8. & 58 & จ & A) & 2 B & & $9:$ & ส & & \&ి \\
\hline 중 & Gros & $a \dot{x}$ & & & & & & & & & & & & & 8 & - & D. & & & a & 01 & & & 0 & $n$ & $\infty$ & $\infty$ & $\infty=$ & $=n$ & $\infty$ & $N$ & $\infty 0$ & & 0. & & 0 & \\
\hline
\end{tabular}

Fig. 2.- Características técnicas de las cerámicas de Caracenilla y Huete.

Consecuentemente con estos tipos de cocción, las cerámicas presentan, en general, unas tonalidades oscuras cuya gradación oscila entre los parduzcos, muy frecuentes en Caracenilla, hasta los plenamente negros de algunas piezas de Huete y Buendia.

El desgrasante más usado ha sido la caliza, prácticamente presente en la totalidad de los fragmentos de Caracenilla, en cuatro de Huete y en Villarrubio. Junto a la caliza, se observa también el cuarzo, únicamente constatado en tres piezas de Caracenilla y en dos de Huete y la mica, en un fragmento de Huete y Buendia. Su tamaño es muy fino y fino.

El acabado que presentan sus superficies es, principalmente, alisado fino, bruñido en trece 
fragmentos de Caracenilla y cinco de Huete y simplemente alisado en un caso en Huete y seis en Caracenilla.

Los bordes son de labios redondeados (ocho en Caracenilla y uno en Huete), aplanados (cuatro en Caracenilla y uno en Huete y Buendía) y apuntados (dos en Caracenilla y uno en Huete). Su dirección es saliente. El diámetro no ha podido determinarse en cuatro casos de Caracenilla, se sitúa entre 5 y $10 \mathrm{cms}$. en una pieza de Caracenilla y Buendía; entre los 10 y los $15 \mathrm{cms}$. en siete de Caracenilla y una de Huete y entre los 15 y los $20 \mathrm{cms}$. en una de Caracenilla, dos de Huete y una de Villarrubio.

El fragmento de fondo plano (n. ${ }^{2} 19$ de Caracenilla), único de estas características del conjunto, posee un diámetro de $6,5 \mathrm{cms}$. (Fig. 6).

\section{Formas cerámicas}

La forma cerámica más frecuente es el cuenco, bien conformando un cuarto de esfera, como en Buendía o en algunas piezas de Huete y Caracenilla, o hemisféricos. Esta importante presencia de cuencos está constatada igualmente en los yacimientos referenciados asignados al "grupo Dornajos", destacando el propio yacimiento epónimo (Galán y Poyato, 1978-79: 76), o los de Ocaña (Toledo), Garnátula de Calatrava (Ciudad Real), Villas Viejas (Cuenca) (Poyato y Galán, 1985) y en otros yacimientos conquenses como los de Cervera del Llano (Chapa et alii., 1979: 6), Acohujate y Villaescusa de Haro (Martínez-Navarrete, 1985). Una gran presencia de cuencos se documentan también en otros yacimientos campaniformes paralelizables con los estudiados como los de Hornos del Segura en Jaén (Maluquer de Motes, 1975: 298) y el Cerro de la Virgen en Ocre (Granada) (Schüle y Pellicer, 1966).

La ausencia de fondos planos, salvo el fragmento de Caracenilla, podría estar señalando unas bases redondeadas para estos cuencos.

Otra forma registrada es el vaso de borde saliente y suave perfil en «S", como el que se observa en las piezas números 1 y 6 de Caracenilla (Lám. I, n. ${ }^{2} 2$ ).

El tamaño de las vasijas, según se desprende de sus diámetros, arcos y grosores máximos, es mediano/pequeño, siendo únicamente un fragmento de pared de Caracenilla el que podría pertenecer, tanto por la amplitud de su arco como por su grosor máximo (13 $\mathrm{mm}$.) a un gran recipiente.

\section{Las decoraciones}

Las decoraciones de las cerámicas conquenses estudiadas presentan claros elementos de contraste con las campaniformes incisas e impresas clásicas.

Estas, a diferencia de los desarrollos decorativos incisos campaniformes más característicos, preferentemente localizados en las superficies externas de los recipientes y en los que la decoración interior, cuando existe, queda relegada, generalmente, a un ligero adorno que apenas suele sobrepasar una franja junto al borde, reflejan una tendencia a la equiparación decorativa entre sus paredes, no tanto por el uso de motivos similares, cuanto por la amplitud que alcanzan en los desarrollos interiores, cubriendo, en un buen número de casos, una superficie cercana al cincuenta por ciento del total, reduciéndose ésta cuando se trata de desarrollos monotemáticos o, excepcionalmente, de más de un tema como ocurre en la pieza n. 237 de Caracenilla (Fig. 3).

Respecto a la ejecución de las decoraciones se observan dos grupos. El primero, está compuesto por las piezas de Buendia, Villarrubio y algunas de Huete (núms. 1, 4 y 5) y Caracenilla (núms. 33, 34-36). En él, se aprecia un gran cuidado y regularidad, encontrándose en la línea de las más "clásicas" decoraciones campaniformes incisas. 

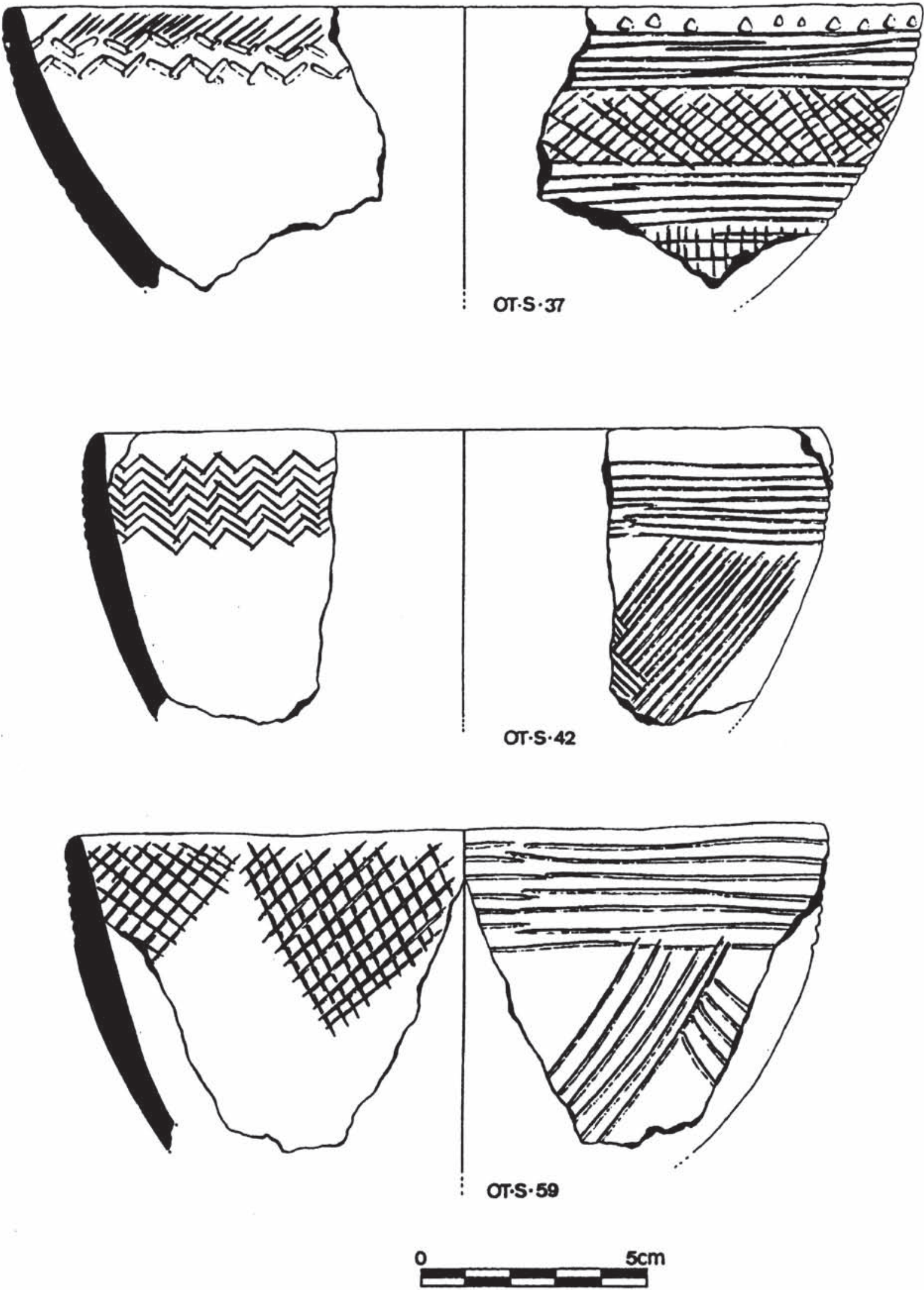

Fig. 3.- Cuencos con decoración incisa e impresa del cerro del Otero (Caracenilla). 
El segundo grupo, más amplio que el anterior, está conformado por el resto de las piezas de Huete y Caracenilla. Estas, aún manteniendo unos motivos similares, muestran un menor cuidado en sus ejecuciones, asemejándose, en su aspecto general, a los conjuntos campaniformes del reborde oriental de la Meseta como los de Somaén (Barandiarán, 1975 y Cajal, 1981) o Almazán en Soria (Revilla Andia y Jimeno Martínez, 1986); los del área de Silos (Delibes y Municio, 1981) en Burgos o Arevalillo (Fernández Posse, 1981) y la Vaquera (Zamora, 1975) en Segovia.

Las decoraciones son, fundamentalmente, incisas. Están bien marcadas, en algunos casos, profundamente. Salvo en la pieza número 37 de Caracenilla, donde se observan restos de una pasta blanca rellenando algunos de los motivos y en Buendia, donde se señala la presencia de la misma (Valiente, 1974: 135), el resto no muestran huellas de un relleno como parte de la decoración. A falta, en los dos casos, de un análisis preciso que determine si se trata de auténtica pasta de incrustación o de concreciones calcáreas.

Entre las decoraciones impresas, hay que destacar los dos fragmentos de bordes con puntillado, sólo al exterior, encontrados en el cerro del Otero en Caracenilla.

El primero (Fig. 4, n. ${ }^{2}$ ) presenta únicamente una banda horizontal puntillada rellena de líneas oblicuas, enmarcada arriba y abajo por sendas lineas puntilladas. Bajo ellas, se sitúa otra banda lisa, ligeramente menos ancha, en cuyo extremo inferior se establece una línea puntillada horizontal que, dadas las dimensiones del fragmento y la forma de su fractura, es imposible determinar si se trata de una única línea o si, por el contrario, delimita una nueva banda de puntillado.

En el segundo (Fig. 4, n. ${ }^{9} 60$ ), la decoración puntillada conforma, al menos, dos bandas horizontales rellenas de reticulado romboidal que alternan con otras más estrechas lisas entre las que se dispone una linea horizontal puntillada.

Estas cerámicas, las primeras con este tipo de decoración que se documentan en la provincia de Cuenca, tienen, no obstante, unos precisos paralelos en otros yacimientos del interior como los madrileños del dolmen de Entretérminos (Losada, 1976) y el Arenero de Miguel Ruiz (Loriana, 1942), especialmente este último por la presencia en uno de sus vasos de bandas horizontales de reticulado oblicuo puntillado y entre las que se establecen líneas horizontales igualmente puntilladas.

Bandas con reticulado romboidal puntilladas alternando con otras lisas u otro tipo de decoración se registran en algunos materiales de yacimientos portugueses (Harrison, 1977: 143-149), en un buen número de yacimientos andaluces, entre los que habría que citar el Cerro de la Virgen, en Orce (Granada) (Schüle y Pellicer, 1966: 29); Almizaraque y Loma de Belmonte, en Almería (Harrison, 1977: 195); Carmona, en Sevilla o Mojácar, en Granada (Castillo, 1928: Lám. LIX), y, ya en el interior, el segoviano de La Tarascona (Delibes y Municio, 1981: 78).

Entre las cerámicas incisas, el motivo más usado en los repertorios decorativos exteriores es la línea horizontal (Fig. 7), generalmente en agrupaciones que oscilan entre las dos (A1) y las, al menos, once (A7) de la pieza número 12 de Caracenilla, predominando los paquetes intermedios de cinco a ocho líneas. Este tema, ampliamente representado en los conjuntos campaniformes peninsulares, se registra en 27 piezas, constituyendo un porcentaje cercano al 70 por ciento del total, amplio margen porcentual que da al conjunto un marcado carácter «rayadon muy cercano a los documentados en yacimientos como los catalanes del área de Salamó (Escornabou, Arbolí, Cartanyá, Cova Fonda de Salamó, etc.) (Harrison 1977: 197-241 y Castillo, 1928: Láms. LXII-LXXV), a otros intermedios de la cuenca del Ebro como Somaén (Barandiarán, 1975: 63-65 y Cajal, 1981: 196-203) o la cueva de Los Casares en Guadalajara (Barandiarán, 1973: 46); a algunos materiales de la cuenca del Duero como el vaso de Pajares de Adaja, en Avila o el cuenco de Tejares de Otero, en Palencia (Delibes, 1977: 2534 y Santa Olalla, 1930: Lám. XIII); a algunos otros del interior como los de Tejar del Sastre, en Madrid (Quero Castro, 1982: 216) o Granátula de Calatrava, en Ciudad Real (Poyato y Galán, 197879: 62) y, finalmente, a los conjuntos andaluces de Almizaraque (Harrison, 1977: 198), el Cerro de la Virgen, en Orce (Granada) (Schüle y Pellicer, 1966: 38-66) o a los de Hornos de Segura, en Jaén (Maluquer de Motes, 1975: 296-298).

La línea horizontal, sólo aparece como tema único en algunos fragmentos de pequeñas dimensiones. En ningun caso, se usa aislado en los desarrollos más amplios, constituyendo, por el 

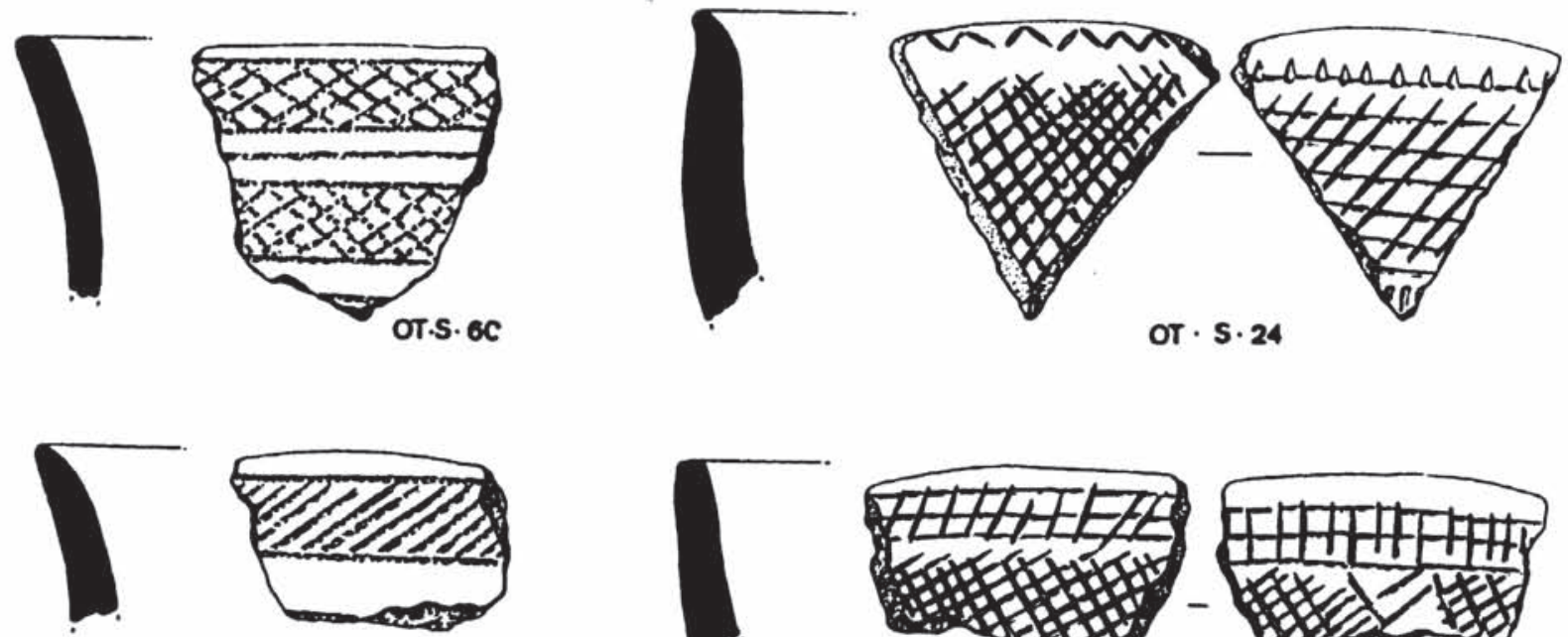

OT. $\mathbf{s} \cdot \mathbf{8}$
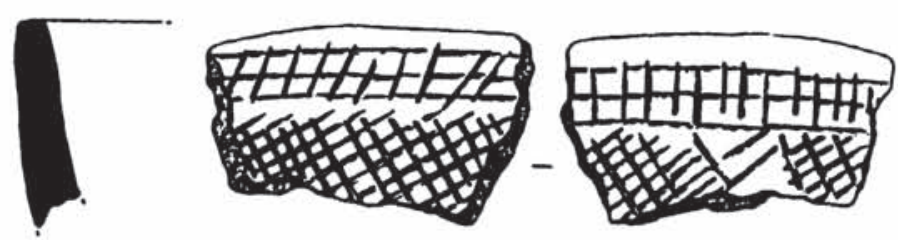

or. s. 32
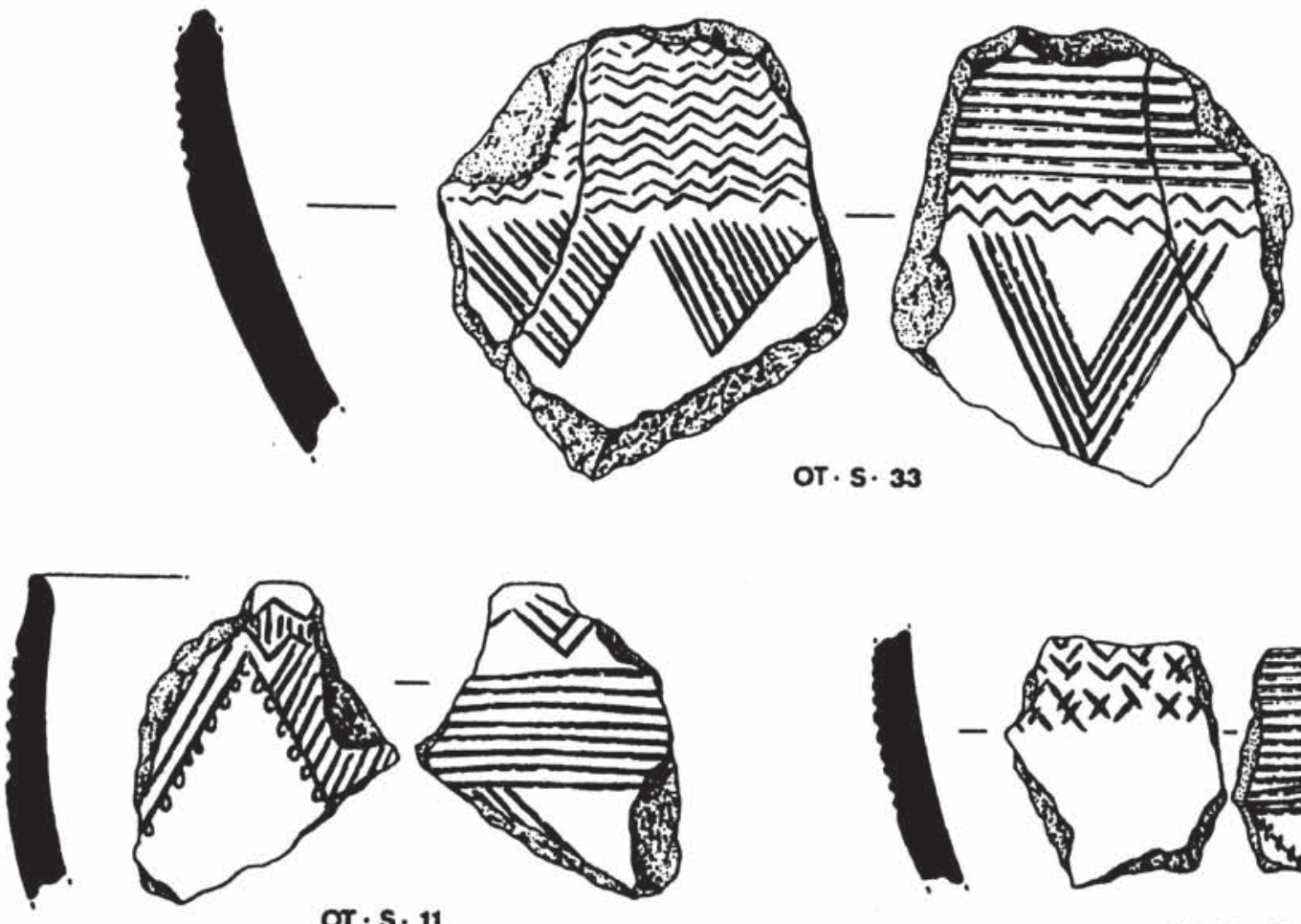

or.s. 11

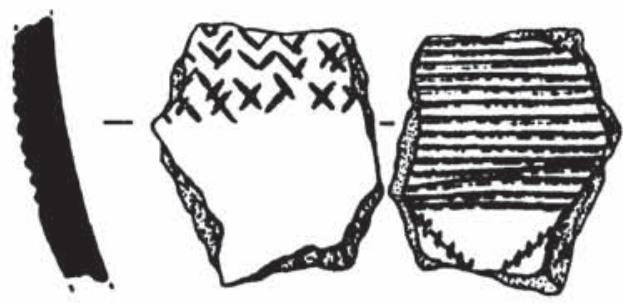

or. $\mathbf{s} \cdot 12$
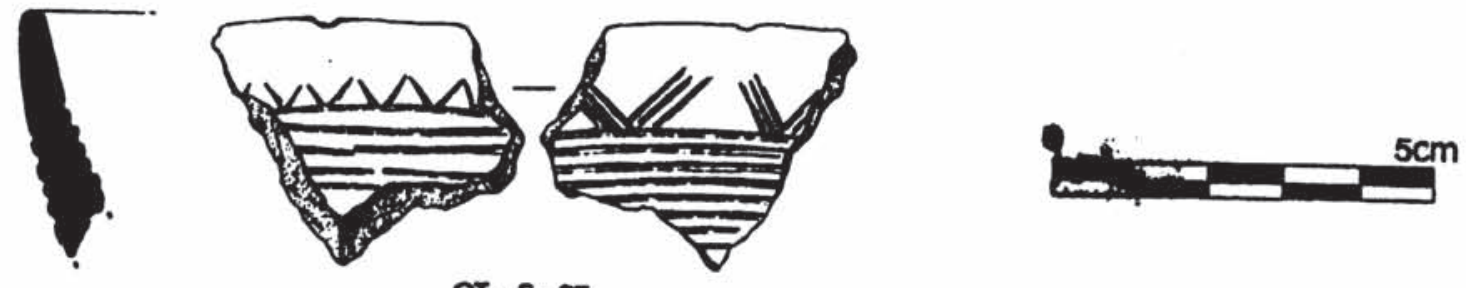

FIG. 4.- Cerámicas puntilladas e incisas (El Otero, Caracenilla). 
contrario, el motivo con el que se registran más asociaciones decorativas. Así lo encontramos en Villarrubio con G1 y G2 (Fig. 6), en Huete con B1, B3, C1 y F3 (Fig. 6) y en Caracenilla con B3, B5, C2, C3, D3, D4, F1, F2, F4, G3, H1, H2 y J1 (Figs. 3, 4 y 5).

La frecuencia en el empleo de este tema queda más resaltada todavía si se tiene en cuenta que otros como B1, B2 y F2 (Figs. 4 y 6) tienen como base las líneas incisas horizontales paralelas cuyo desarrollo interrumpen.

Estas series comienzan la decoración o se sitúan inmediatamente debajo de otro tema inicial o entre otros intermedios. En algunos casos, estas agrupaciones se encuentran delimitadas arriba y abajo por «lineas cosidas» (tema H1) (Lám. I, n. ${ }^{2} 7$ ), desarrollo para el que se posee un buen paralelo en los materiales de Granátula de Calatrava, en Ciudad Real (Poyato y Galán, 1978-79: 62).

Contrariamente al frecuente uso de este motivo en los exteriores, en los interiores únicamente lo registramos en un fragmento con, al menos, cinco líneas (A1) sobre las que se dispone una serie horizontal de zig-zag (Fig. 4, n. ${ }^{2}$ 27). Los referentes para este desarrolo interior son escasos, recogiendo únicamente los del yacimiento tarraconense de Benifallet (Harrison, 1977: 207).

Por su parte, el motivo interior más usado es la serie horizonal de zig-zags (Fig. 7) incisos. Estos están conformados bien por pequeñas incisiones/impresiones apuntadas, bien por cortas líneas incisas oblicuas. Este motivo se observa de forma individual o asociado a otros en 18 fragmentos, lo que supone un porcentaje cercano al cuarenta por ciento del total estudiado, encontrándose presente en tres de los cuatro yacimientos recogidos: Villarrubio, Huete y Caracenilla.

Este motivo es, sin duda, el tema decorativo más característico del horizonte de los campaniformes incisos. Generalmente usado en forma monotemática, variando la amplitud de su desarrollo entre una y las, al menos, veinte que se documentan en el interior de una de las piezas del estrato A3-B2 de Hornos de Segura (Jaén) (Maluquer de Motes, 1975: 297). Siendo, no obstante, lo más común, los desarrollos de menos de cinco. Este último yacimiento, es el referente más preciso para la amplitud del tema en algunas de las cerámicas de Caracenilla y Huete (Figs. 4 y 6 ).

Por el contrario, este tema se encuentra poco presente en los exteriores, donde además, su desarrollo es muy reducido, entre una (C1) y tres (C3).

Junto a las líneas incisas paralelas horizontales, el motivo más repetido en los exteriores son las retículas que conforman bandas horizontales o rellenan otros temas.

En el primer caso (Fig. 7) diferenciamos cuatro tipos. El primero (B1 y B2) consiste en el entrecruzamiento de lineas incisas oblicuas con otras horizontales paralelas ya existentes. La amplitud de esta retícula oscila entre las tres líneas horizontales y las ocho. Este motivo está presente en las piezas números 1,2 y 3 de Huete (Fig. 6. Lám. II, n. ${ }^{2}$ ) y en los números 3, 6 y 24 de Caracenilla (Fig. 4).

El segundo (B3) tipo está constituido por el entrecruzamiento de líneas incisas paralelas oblicuas con otras igualmente oblicuas pero de sentido contrario, formando una banda horizontal delimitada arriba y abajo por sendas líneas incisas horizontales. Este tipo está presente en las piezas números 1 y 4 de Huete (Fig. 6. Lám. II, n. ${ }^{2}$ 2) y en la número 37 de Caracenilla (Fig. 3).

El tercer tipo (B4) podría considerarse como una variante del anterior del que se diferencia por la ausencia de líneas que lo enmarcan y por la amplitud de la propia retícula. Este tema únicamente lo registramos en la pieza número 1 de Caracenilla.

Finalmente el B5, se define por el entrecruzamiento de líneas incisas paralelas verticales con otras horizontales que conforman un ajedrezado. Este tema se emplea en las piezas números 32, 37 y 43 de Caracenilla (Figs. 3 y 4).

El reticulado se emplea también para rellenar triángulos invertidos (tipo D2) o amplias bandas zigzagueantes (D3). En ambos, se trata de retículas obtenidas por el entrecruzamiento de líneas oblicuas incisas paralelas con otras de sentido contrario o verticales, como ocurre en las números 34-36 de Caracenilla (Fig. 5).

En el interior; se observan retículas de los tipos B1 y B2 en las piezas números 32 y 43 (B1) y 39 (B2) de Caracenilla (Fig. 4). En el primer caso están asociadas a D1 y C3 respectivamente y en el segundo, a C2. 


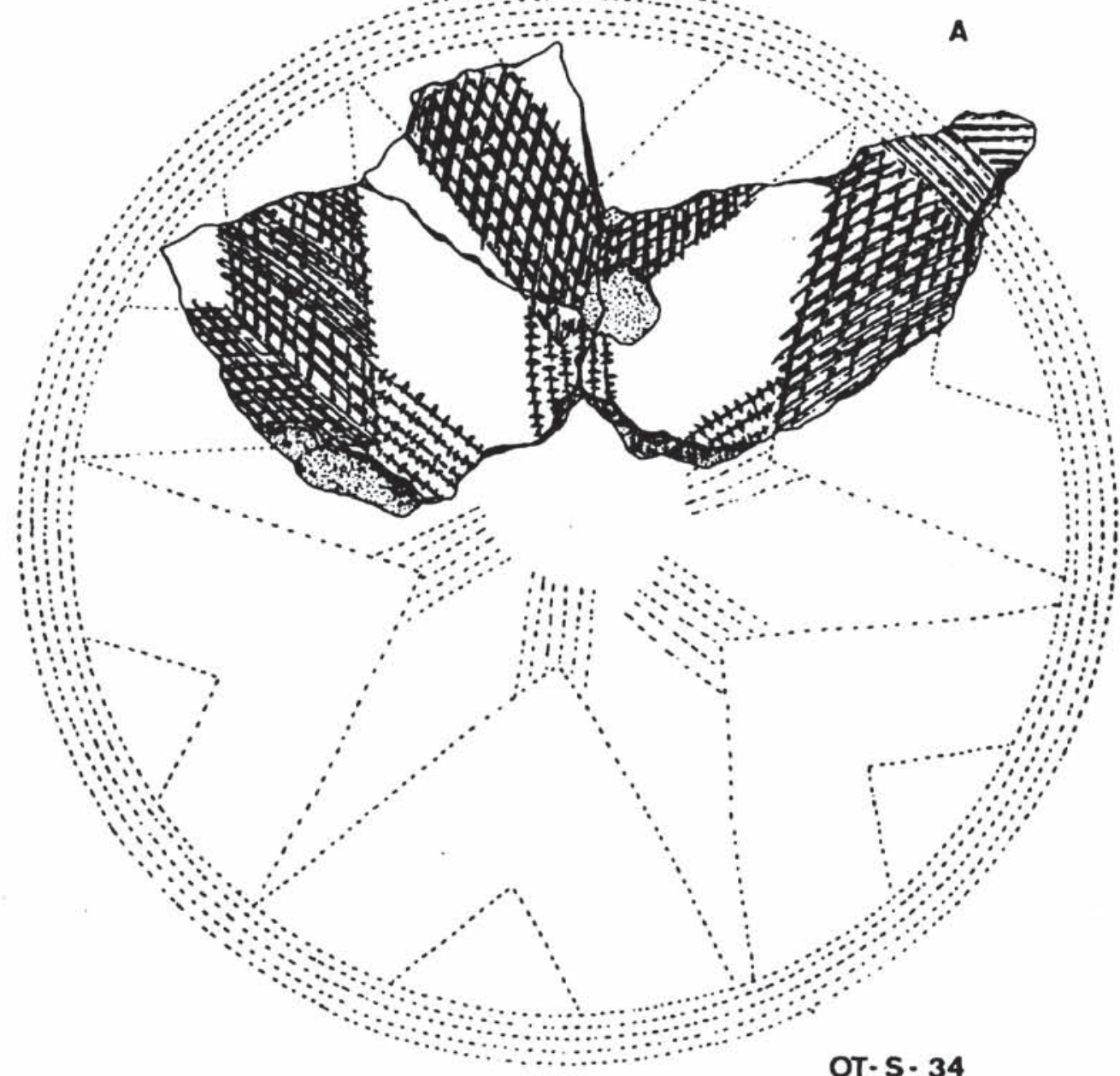

OT-5· 34

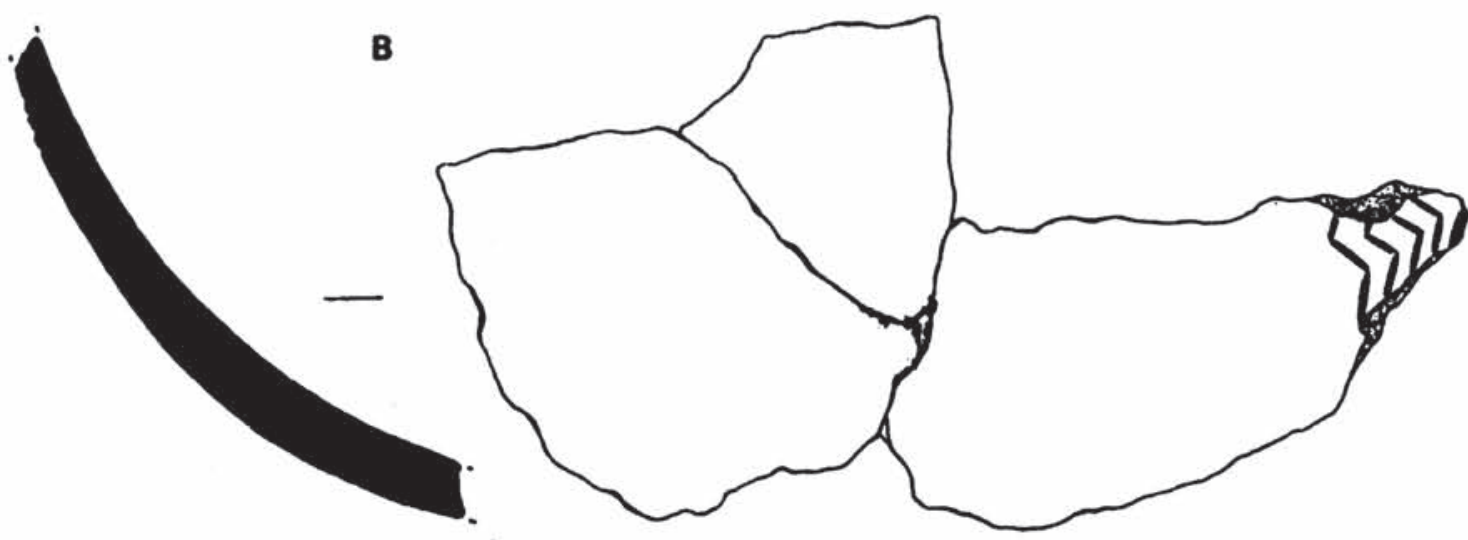

0

$5 \mathrm{~cm}$

FIG. 5.- Fragmento de cuenco inciso de Caracenilla. A) Desarrollo decorativo exterior y B) Perfil y decoración interior. 


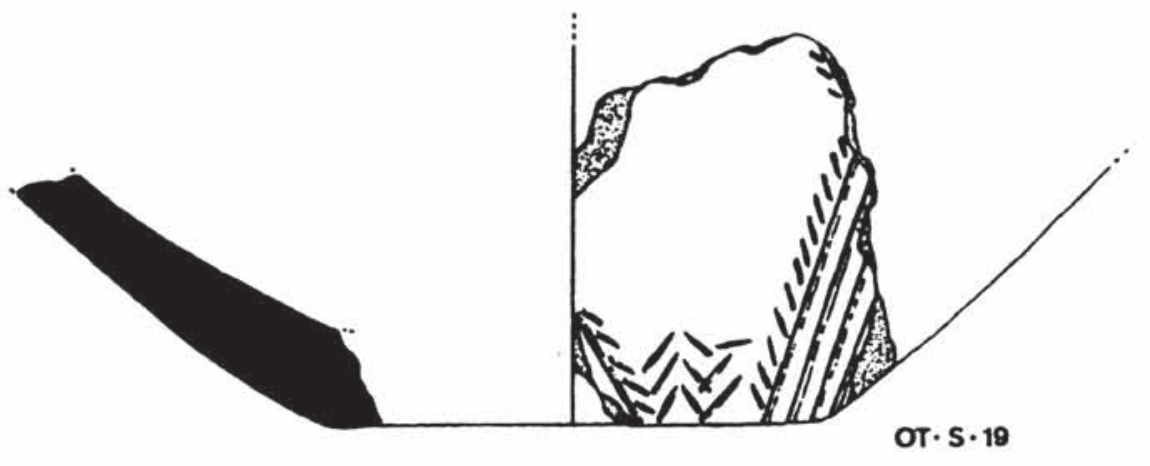

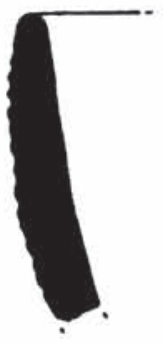

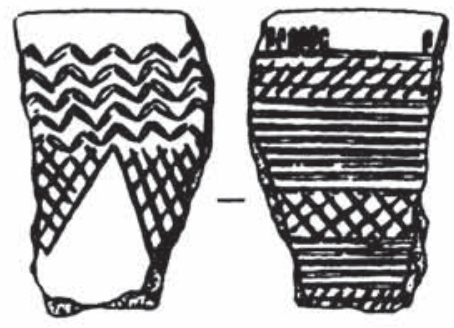

H.1

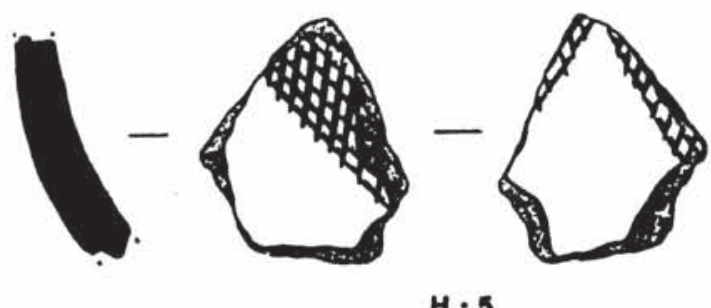

$\mathbf{H} \cdot \mathbf{5}$
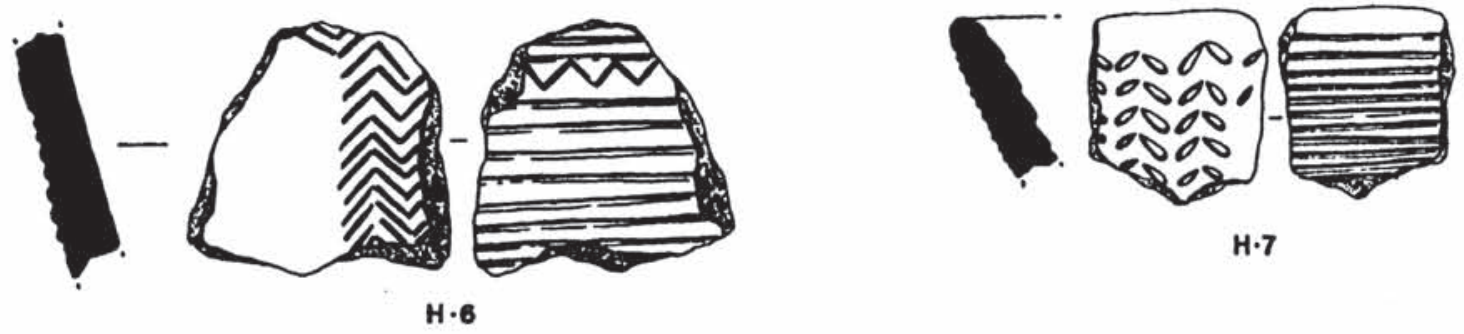

H.7
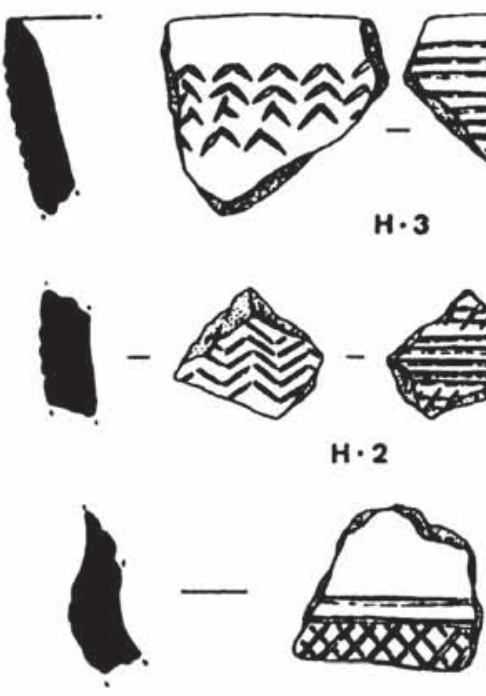

H. 4

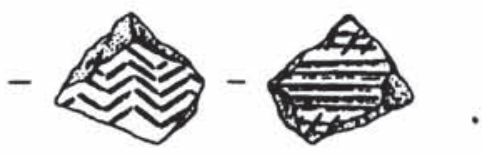

$H \cdot 2$

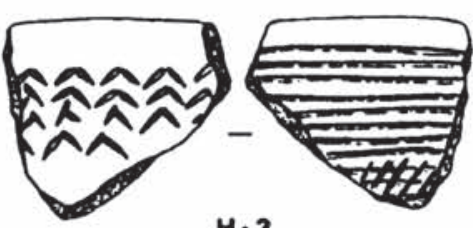

H.3

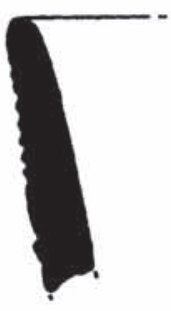

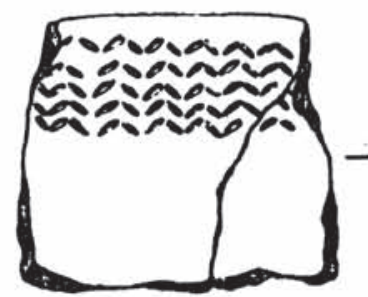

V $\cdot 1$

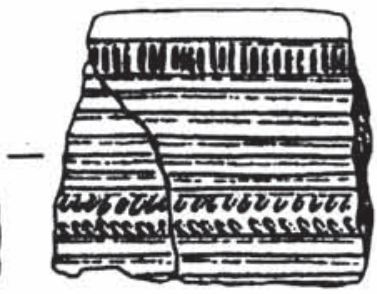

0 $5 \mathrm{~cm}$

Fig. 6.- Cerámicas incisas e impresas. Caracenilla (OT/S/19), Huete (H1 a H7) y Villarrubio (VI. 1). 

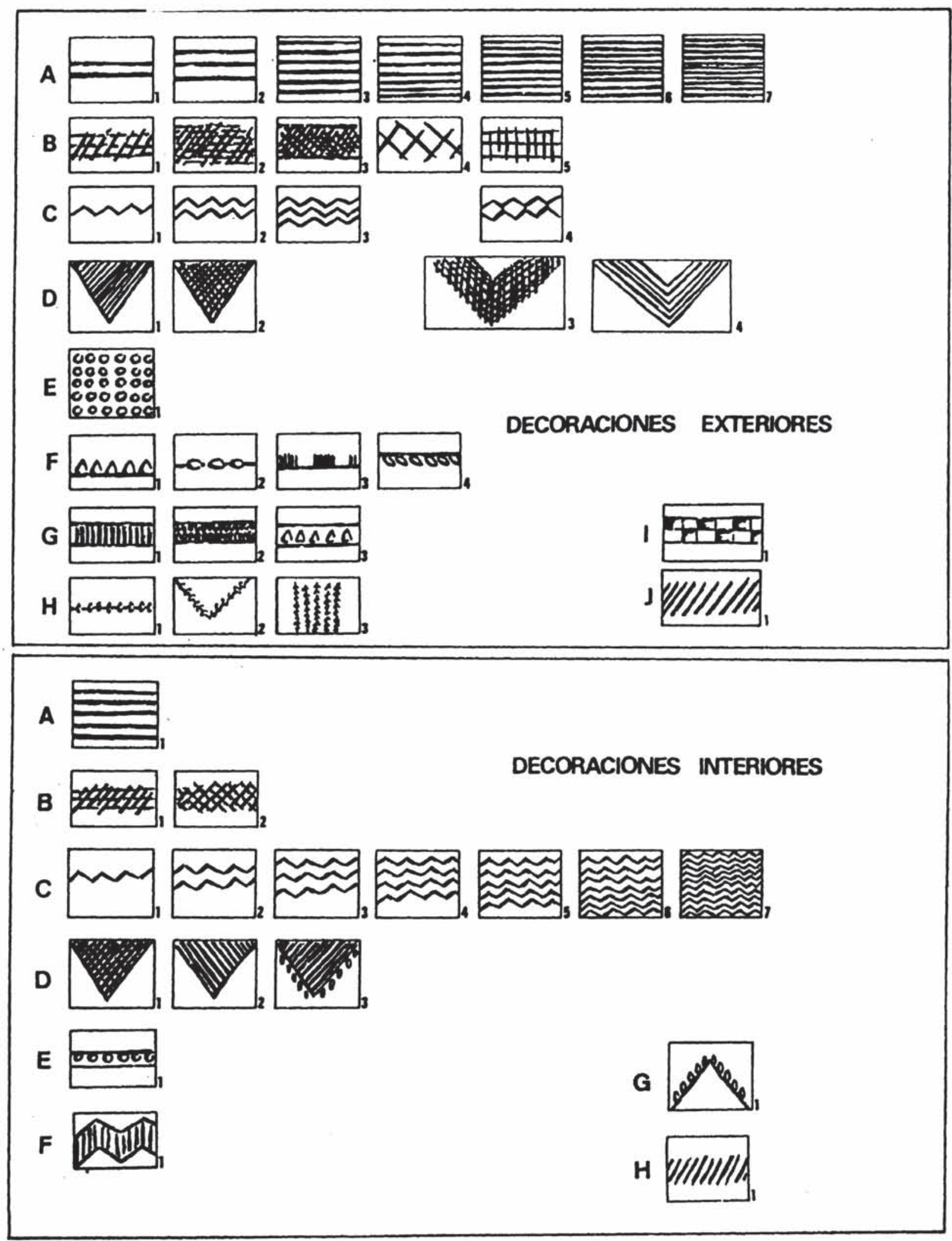

FIG. 7.- Repertorio de temas decorativos registrados en las cerámicas analizadas. Cerámicas incisas e impresas del Otero (Caracenilla).

Fragmentos de cuencos. 1) Buendía y 2) Huete. 
Estas disposiciones reticuladas son un tema muy empleado en los desarrollos decorativos campaniformes incisos. Pero dentro de ellos son mucho menos frecuente las denominads por nosotros B1 y B2 para los exteriores y B1 para los interiores. Así, no se registran en los repertorios clásicos del interior peninsular (Ciempozuelos, Ventorro, Fábrica de Euskalduna, etc.) ni aún en los de los grupos catalanes o andaluces. Sin embargo, si se encuentran muy presentes, tanto en los exteriores como en los interiores, en el yacimiento soriano de Somaén (Barandiarán, 1975: 29-43 y Cajal, 1981: 196-203), fundamentalmente en cuencos, constituyendo la mayor parte del denominado por Barandiarán tipo Ia, aunque también lo está en otros como Ib, Ic, Ik, etc. Este tipo lo encontramos igualmente, en la cueva segoviana de Arevalillo (Fernández Posse, 1979: 59 y 1981: 60) y en el exterior de algunas cerámicas del yacimiento soriano de «El Guijan (Revilla Andia y Jimeno Martínez, 1986: 171), así como en los Casares (Guadalajara) (Barandiarán, 1973: 46), igualmente en exteriores en Tudela (Navarra) (Bienes Calvo, 1985: 256), en algunas cerámicas del área de Silos (Burgos) (Delibes y Municio, 1981: 81) y en el yacimiento vallisoletano de Arrabal del Portillo (Fernández Manzano y Rojo Guerra, 1986: 56-63), siendo este último, al parecer, el único referente, hasta el momento, para este tipo en el interior de la cuenca del Duero, tanto para los exteriores como para los interiores.

Las retículas de los tipos B1 y B2 (exteriores) y B1 (interiores) se encuentran ausentes de los repertorios del ugrupo Dornajos" (Galán y Poyato, 1978-79: 80; Galán y Fernández Vega, 1982-83: 4347 y Poyato y Galán, 1985), donde sí se registran, y muy ampliamente, las de los tipos B3, B4 y B5 para exteriores y B2 para los interiores.

Otro motivo que se utiliza en la decoración de ambas superficies son los triángulos invertidos rellenos, bien con rayado oblicuo (D1 para los exteriores y D2 para los interiores) o con retícula oblicua (D2 para los exteriores y D1 para los interiores). En el caso de los interiores registramos una variante (D3) consistente en la ampliación o adosado a las líneas que los enmarcan de pequeñas impresiones a modo de eflecos" (Fig. 4, n..$^{2} 11$ ).

En los exteriores, este tema aparece con frecuencia en un buen número de yacimientos con campaniforme inciso, siendo, no obstante, inexistente en el interior de las piezas de estos mismos contextos.

En los interiores, se disponen, generalmente, asociados a otros (series de zig-zags horizontales, los más frecuentes, cinta quebrada rellena con rayado vertical inciso y retícula horizontal), aunque también se registran de forma monotemática (Fig. 3, n.2 59). En aquellos fragmentos en los que por sus dimensiones es posible contemplar en su totalidad los desarrollos decorativos interiores, este tema completa, en todos los casos, las series decorativas constituyendo el último motivo empleado, aspecto éste que también se observa en el único paralelo que poseemos para este tema como es el fragmento de cuenco del Alto de Mazacota en Ocaña (Toledo) (González Simancas, 1934, Harrison, 1977: 185 y Poyato y Galán, 1985), incluido, en algunas publicaciones, entre los materiales de la cueva segoviana de La Tarascona (Delibes y Municio, 1981: 80) (4).

La ausencia de este tema en los interiores de los materiales campaniformes incisos y su presencia en los considerados como pertenecientes al "grupo Dornajos" hace que tales disposiciones se acerquen más a las de este último grupo. Sin embargo, hay que señalar que en él no se registran de forma monotemática o completando las series decorativas, como sucede en estas piezas, ya que o bien encabezan los desarrollos junto a otros motivos (Cervera del Llano) o bien, se sitúan en la parte central de los mismos (Dornajos, Cervera de Llano, Villaescusa de Haro, etc.). En idéntico contexto, muy próximo a «Dornajos* habría que encuadrar la variante interior D3.

El motivo F1 (estrecha banda quebrada rellena con pequeñas incisiones paralelas verticales) (Fig. 4, n. $\left.{ }^{2} 11\right)$ destaca del resto de los temas interiores (E1, G1 y H1). Este, siendo un motivo muy característico en los repertorios campaniformes incisos "no es frecuente" ' (Lucas. Pellicer y Blasco Bosqued, 1980: 19) en los interiores registrándolo, por ejemplo, en el dolmen burgalés de "Las

(4) Dato que debemos a la amabilidad de D. Luciano Municio (Arqueólogo Territorial de la Delegación de Cultura de Segovia. Junta de Castilla y León) y de J. Manuel Rojas Rodríguez Malo. 
Arnillas» (Delibes et alii., 1986: 27) y en los yacimientos sorianos de «El Perchel» en Arcos del Jalón (Lucas Pellicer y Blasco Bosqued, 1980: 16) y «El Guijar» en Almazán (Revilla Andia y Jimeno Martínez, 1986: 189). Tampoco es frecuente en el «grupo Dornajos» donde, no obstante, está presente en el exterior de un fragmento de Cervera del Llano (morrota de los Cotos) (Chapa et alii., 1979: 6) y en el interior de otro de Villaescusa de Haro (Martínez Navarrete, 1985) ambos en la provincia de Cuenca.

Por su parte, los demás motivos exteriores, salvo E1, D5 y el exciso I1, así como sus disposiciones y asociaciones se encuentran ampliamente representados en los registros más típicos campaniformes por lo que no vamos a insistir en ellos ni en sus paralelos. Señalar solamente que este hecho constituye un importante elemento diferenciador con respecto a la tipología decorativa del "grupo Dornajos» donde no obstante, también se reflejan algunos de estos temas como el D4.

Finalmente, concluimos este apartado con el fragmento de cuenco de Buendía en el que registramos una auténtica «excisión», entendida como el resultado de la extracción de arcilla y no de la impresión profunda o "pseudoexcisión». Esta excisión, que conforma una banda de ajedrezado horizontal, se ha producido tras el marcado de una retícula cuadrada en la correspondiente banda, procediendo después a su extracción, obteniendo espacios cuadrados, más o menos regulares, según las zonas (Lám. II, n. ${ }^{9}$ 1).

Esta cerámica se encontraría en la línea de las excisiones documentadas en Tudela (Navarra) (Bienes Calvo, 1985: 257) y en el Castillo de Burgos (Uribarri et alii., 1987: 80) especialmente en este último yacimiento cuyos ajedrezados rectangulares constituyen su más preciso paralelo.

\section{CONSIDERACIONES FINALES}

Estas cerámicas y sus correspondientes desarrollos decorativos como principal elemento identificativo, se situarían, según los datos hoy disponibles, a medio camino entre los registros típicos campaniformes incisos y los del "grupo Dornajos». De los primeros, poseen, fundamentalmente, sus motivos y seriaciones exteriores y de los segundos, las interiores, cuyas disposiciones bien pueden calificarse, en algunos casos, como «extrañas» a los repertorios campaniformes.

Los puntos de contacto con ambos conjuntos cerámicos y las correspondientes diferencias observadas entre ellos, estarían señalando, más que un cúmulo de influencias (que indudablemente existen), diversos momentos de un proceso transformativo cuya línea principal sería más de tipo superficial (entendida ésta como modificaciones espaciales de los motivos) que estructural. Esto supondría, que los temas decorativos permanecerían constantes a lo largo de la práctica totalidad del proceso, con algunas variaciones de tipo interpretativo en los momentos finales (Dornajos), mientras que sí cambiarían, y sustancialmente, sus disposiciones espaciales, la amplitud de los mismos y, principalmente, sus asociaciones con otros en los repertorios decorativos exteriores y, fundamentalmente, interiores.

Este mismo proceso transformativo, o muy similar, es el que pueden estar reflejando los materiales de dos yacimientos campaniformes andaluces, el Cerro de la Virgen, en Orce (Granada) (Schüle y Pellicer, 1966) y Hornos de Segura, en Jaén (Maluquer de Motes, 1975); constituyendo ambos, uno de los paralelos más claros para nuestras cerámicas.

En el primero, junto a series decorativas plenamente identificables como campaniformes incisas, tanto por sus motivos como por sus disposiciones y desarrollos, se registran, en algunos de sus interiores, unas decoraciones que contrastan claramente con estos repertorios exteriores. Tanto es así, que son consideradas en la actualidad como pertenecientes al "grupo Dornajos" (Poyato y Galán, 1985).

Las cerámicas de Hornos de Segura, cuyos desarrollos decorativos son perfectamente paralelizables con los de Caracenilla, comienzan a presentar ya ciertas diferencias respecto a los registros 
campaniformes incisos más característicos tanto en los exteriores -motivos menos variados y más amplios-, como en los interiores - mayores desarrollos decorativos-, aunque manteniendo motivos únicos típicos como las series horizontales de zig-zags.

Tomando como referencia las fechas radiocarbónicas del Cerro de la Virgen de Orce (Delibes, 1978: 89) y la correlación entre la secuencia de este yacimiento y la de Hornos de Segura, también con una ocupación argárica, habria que considerar que tales procesos transformativos habrían tenido lugar a lo largo de los primeros siglos del II milenio antes de Cristo.

Hacia momentos cercanos al 2000 a.C. estarían apuntando, igualmente, las cerámicas puntilladas geométricas de Caracenilla y los materiales más semejantes a los nuestros (Huete) de Somaén (Delibes y Municio, 1981: 75 y Cajal, 1981: 217).

En este planteamiento, la fecha de 1600 a.C obtenida en "Los Dornajos» (Galán y Fernández Vega, 1982-83: 42) estaría marcando, quizá, los momentos de pleno desarrollo de estos grupos y cuyo proceso de formación coincidiría, a grandes rasgos, con el propuesto para Huete con los materiales más antiguos y Caracenilla, cuyas cerámicas constituirian, a su vez, los más directos y precisos antecedentes de las de este grupo y cuya data habría que situarla sobre el 1700 a.C. Esta fecha quedaría confirmada, de alguna manera, por la punta Palmella encontrada en "Los Dornajos", dado que para este tipo metálico se proponen unos márgenes cronológicos situados entre el 1800 a.C.y el 1650 a.C (Delibes y Fernández Miranda, 1981: 160) y por la presencia en los yacimientos de Huete, Caracenilla y Villarrubio de típicas cerámicas Cogotas I (Martínez González y Martínez Navarrete, 1985), materiales que como se documenta en la cueva segoviana de Arevalillo, pueden llegar a conectar con determinadas especies campaniformes en pleno siglo XIV a.C. (Fernández Posse, 1981: 66).

Estas cronologías, en algunos, casos, correrían muy próximas a las registradas en otros yacimientos de la Edad del Bronce conquense como «El Castillejo» en Parra de las Vegas, para el que se le supone una ocupación entre el 2000 a.C. y el $1280 \pm 110$ a.C. (Martínez Navarrete y Valiente, 1983: 149), «El Recuenco» en Cervera del Llano con $1830 \pm 95$ y $1290 \pm 95$ a.C. (Martínez Navarrete y Valiente, 1983: 154) y «El Colmenar» en Landete, con 1600 a.C. (Alvarez et alii., 1984: 33). Yacimientos con los que, en principio y a falta de unos indicadores más completos (cronologías, materiales, etc.) no parecen tener una relación muy directa.

\section{AGRADECIMIENTOS}

A D. Santiago Serrano, por su amabilidad al proporcionarnos los materiales del «Otero" (Caracenilla) recogidos en este estudio; así como a su esposa Dña. María Carballido por las muchas atenciones recibidas en su casa durante el tiempo que allí duró nuestro trabajo.

A la Dra. M." Isabel Martínez Navarrete (C.S.I.C. Madrid), por los datos, puntualizaciones y correcciones aportadas, así como las facilidades prestadas para la consulta de su Tesis Doctoral.

A la Dras. Catalina Galán Saulnier y Carmen Poyato Holgado (Universidad Autónoma de Madrid) que posibilitaron la observación de las cerámicas inéditas de "Los Dornajos" y nos facilitaron su comunicación (en prensa) al I Congreso de Historia de Castilla-La Mancha.

A D. Manuel Osuna Ruiz (Delegación de Cultura de la Junta de Castilla-La Mancha), quien nos alentó en nuestro trabajo.

Al personal del Museo Provincial de Cuenca: D. Juan Manuel Millán Martínez, Dña. Adela M. ${ }^{a}$ Muñoz Requena, Dña. Juana M. ${ }^{a}$ Huélamo Gabaldón, D. Jesús López Requena y D. Aurelio Lorente, a quien, junto a $\mathrm{D}$. Carlos Calvo, debemos la realización de las fotografías que ilustran nuestro texto.

Finalmente, a Dña. Isabel Leis Muñoz, colaboradora con el autor en la elaboración de una buena parte de los dibujos y on la recogida, documentación y estudio de los materiales. 


\section{BIBLIOGRAFIA}

Alvarez, J., Bernal, C., Carrasco, A. y Pérez de la Sierra, J. V. (1984): «Memoria de excavaciones arqueológicas del yacimiento de "El Colmenar" (Landete, Cuenca)». Noticiario Arqueológico Hispánico, 18. Madrid.

Asouerino, M." D. (1978): «Cova de la Sarsa (Bocairente, Valencia). Análisis estadístico y tipológico de materiales sin estratigrafian. Saguntum, 13.

Barandiarán, I. (1973): «Excavaciones en la cueva de Los Casares (Riba de Saelices, Guadalajara)». Excavaciones Arqueológicas en España, 76. Madrid.

- (1975): «Revisión estratigráfica de la cueva de La Mora (Somaén, Soria)». Noticiario Arqueológico Hispánico. Prehistoria, 3: 9-71. Madrid.

Bienes Calvo, J. J. (1985): «Nuevos hallazgos de cerámicas campaniformes en Tudela (Navarra)». Actas del XVII Congreso Nacional de Arqueología, (Logroño, 1983): 249-257. Zaragoza.

Cajal Santos, N. (1981): «Materiales de la cueva de La Mora (Somaén, Soria)». Trabajos de Prehistoria, 38 : 193 224. Madrid.

CASTILlo YURRTtA, A. (1928): «La Cultura del Vaso Campaniformew. Universidad de Barcelona. Barcelona.

Coll, J., Cooper, E., Huelamo, J. M. y Solías, J. M. (1986): "El Castillo de Puebla de Almenaran. Actas del I Congreso de Historia del Marquesado de Villena (Albacete). En Prensa.

Chapa, T., López Garcia, P. y Martinez Navarrete, M." I. (1979): «El poblado de la Edad del Bronce de "El Recuenco" (Cervera del Llano)». Arqueología Conquense, IV. Cuenca.

DeliBes de CASTRO, G. (1977): «El Vaso Campaniforme en la Meseta Norte española». Studia Archaeologica, 46. Valladolid.

- (1978): «Carbono 14 y fenómeno campaniforme en la Península Ibérica». C. 14 y Prehistoria de la Península Ibérica. Fundación Juan March: 83-94. Madrid.

Delibes, G. y Fernández Miranda, M. (1981): «La tumba de Celada de Rublecedo (Palencia) y los inicios del Bronce Antiguo en el valle medio y alto del Pisuergaw. Trabajos de Prehistoria, 38: 154-192. Madrid.

DeliBES, G. y MuNicio, L. (1981): «Apuntes para la secuencia campaniforme en el oriente de la Meseta Norte». Numantia, I: 65-83.

Delibes, G., Rojo, M. y Sanz Minguez, C. (1986): «Dólmenes de Sedano. II. El sepulcro de corredor de Las Arnillas (Moradillo de Sedano, Burgos)». Noticiario Arqueológico Hispánico, 27: 7-39. Madrid.

FERNÁNDEZ POSSE, M." D. (1979): «Informe de la primera campaña (1977) en la cueva de Arevalillo (Segovia)». Noticiario Arqueológico Hispánico, 6: 52-87. Madrid.

- (1981): «La cueva de Arevalillo de Cega (Segovia)». Noticiario Arqueológico Hispánico, 12: 44-84. Madrid.

Fernández Manzano, J. y Rojo Guerra, M. (1986): "Notas sobre el yacimiento campaniforme de Arrabal de Portillo (Valladolid)». Noticiario Arqueológico Hispánico, 27: 42-74. Madrid.

Galán Saulnier, C. y Poyato Holgado, C. (1978-79): «Excavaciones en Los Dornajos (La Hinojosa, Cuenca)». Cuadernos de Prehistoria y Arqueología, 1: 71-80. Universidad Autónoma de Madrid. Madrid.

Galán Saulnier, C. y Fernández Vega, A. (1982-83): „Excavaciones en Los Dornajos (La Hinojosa, Cuenca)». Cuadernos de Prehistoria y Arqueología, 9: 31-48. Universidad Autónoma de Madrid. Madrid.

GonzÁlez SimancaS, M. (1934): «Excavaciones en Ocaña». Memorias de la Junta Superior de Excavaciones y Antiguedades, 130. Madrid.

GUSI JERNER, F. (1972): «Hallazgo de cerámicas tipo "impresa mediterránea" con decoración interior incisa». Pyrenae, 8: 53.

HARRISON, R. J. (1977): "The Bell Beaker Cultures of Spain and Portugal». American School of Prehistoric Research. Peadbody Museum. Harvard University. Bull. 35.

Jiménez PéreZ, A. (1985): "La cerámica vidriada de la alcazaba de Huete (Cuenca)». Actas del I Congreso de Historia de Castilla-La Mancha. (Ciudad Real, 1985). En prensa.

LORIANA, MARQUÉS DE (1942): «Nuevos hallazgos de vaso campaniforme en la provincia de Madrid». Archivo Español de Arqueología, 47: 161-167.

LOSADA, H. (1976): «El dolmen de Entretérminos (Madrid)». Trabajos de Prehistoria, 33: 209-226. Madrid.

LuCAS M." R. (1986): «El fenómeno megalítico: estado actual de la investigaciónw. Actas de la Mesa Redonda sobre Megalitismo Peninsular en el XV aniversario de la Asociación Española de Amigos de la Arqueologia (814 Octubre 1984). 11-20. Madrid.

Lucas Pelucer, M." R. y Blasco Bosoued, C. (1980): «El habitat campaniforme de "El Perchel" en Arcos del Jalón (Soria)»: Noticiario Arqueológico Hispánico, 8: 11-68. Madrid.

MARTínez GonZAlez, J. M." y MARTinez NAVARRETE, M." I. (1985): «La ocupación del final de la Edad del Bronce en el Castillo de Huete (Cuenca)». Actas del I Congreso de Historia de Castilla-La Mancha. (Ciudad Real, 1985). En prensa.

MARTINEZ NAVARRETE, M." I. (1984): «El comienzo de la metalurgia en la provincia de Madrid: La cueva y cerro de Juan Barbero (Tielmes, Madrid)». Trabajos de Prehistoria, 41: 17-128. Madrid.

- (1985): «La Edad del Bronce en la Submeseta suroriental: Una revisión crítica». Tesis Doctoral (inédita). Universidad Complutense de Madrid. Madrid. 
- (1987): «Los primeros periodos metalúrgicos». En Catálogo de la Exposición *130 años de Arqueologia Madrileñan: 58-81. Madrid.

Martinez Navarrete, M." I. y Valiente Canovas, S. (1983): «El cerro del Castillejo (La Parra de Las Vegas. Cuenca)». Noticiario Arqueológico Hispánico, 16: 58-223. Madrid.

Osuna RuIZ, M. (1974): «Poblamiento primitivo de la provincia de Cuenca». Revista Cuenca. Cuenca.

Poyato Holgado, C. y Galán Saulnier, C. (1978-79): "Hallazgo de materiales campaniformes en "Oretum", Granátula de Calatrava (Ciudad Real)». Cuadernos de Prehistoria y Arqueologia, 5-6: 59-69. Universidad Autónoma de Madrid. Madrid.

- (1985): «Las cerámicas del "Grupo Dornajos" de la Mancha Oriental». Actas del I Congreso de Historia de Castilla-La Mancha. (Ciudad Real, 1985). En prensa.

Quero Castro, S. (1982): «El poblado del Bronce Medio de Tejar del Sastre (Madrid)». Estudios de Prehistoria y Arqueología Madrileñas, 1: 185-247. Madrid.

Revilla Andia, M.“" L. y Jimeno Martinez, A. (1986): «El horizonte campaniforme de "El Guijar”, Almazán (Soria)». Numantia, II: 159-192.

Schule, W. y Pellicer, M. (1966): «El Cerro de la Virgen, Orce (Granada)». Excavaciones Arqueológicas en España, 46. Madrid.

Santa Olalla, J. (1930): «Cerámica incisa y cerámica de la cultura de vaso campaniforme en Castilla la Vieja y Asturiasw. Anuario de Prehistoria Madrileña, I. Madrid.

Santos Garcí, J. A., Moncó Garcí, C. y Jiménez Pérez, A. (1985): «La alcazaba de Huete. Avance de las excavaciones realizadas en 1985». Actas del I Congreso de Historia de Castilla-La Mancha. (Ciudad Real, 1985). En prensa.

Valiente CÁnovas, S. (1974): «Fragmento de cuenco campaniforme aparecido en Buendía (Cuenca)». Cuadernos de Prehistoria y Arqueología, 1: 133-138. Universidad Autónoma de Madrid. Madrid.

- (1981): «Pico de la Muela (Valera de Abajo, Cuenca)». Noticiario Arqueológico Hispánico, 12: 87-134. Madrid.

Uribarki Angulo, J. L., Martínez González, J. M.^ y Leis MuÑoz, I. (1987): «Primeros asentamientos humanos en la ciudad de Burgos. I.- El Castillo y el Cerro de San Migueln. Burgos.

Zamora CANelladA, A. (1975): "Contribución al estudio del Bronce Final en la Meseta Norte: Las cerámicas incisas de la cueva de La Vaquera o Fuentedura Torreiglesias (Segovia)». Actas del XIII Congreso Nacional de Arqueología (Huelva, 1973): 529-546. Zaragoza. 


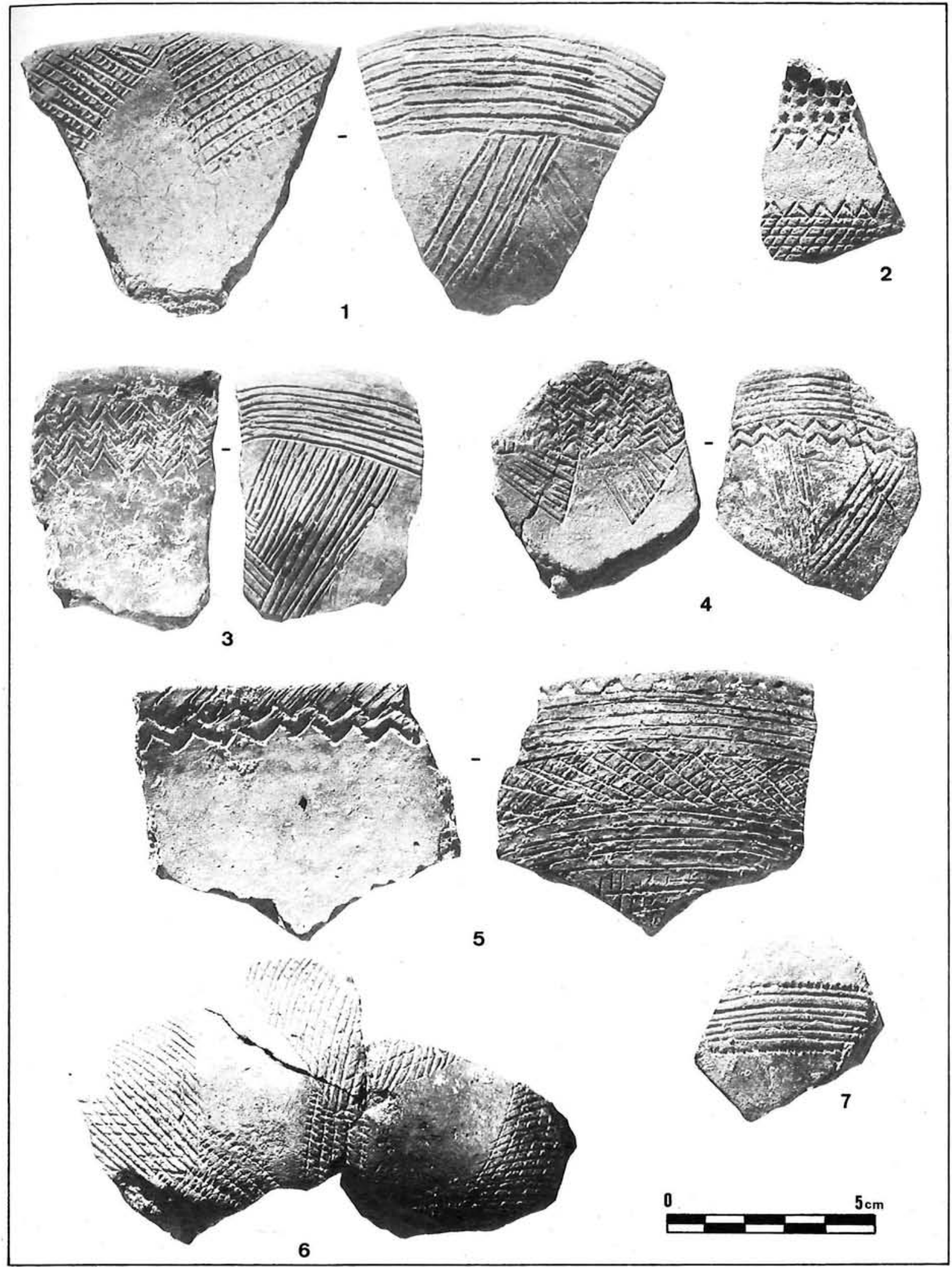

Cerámicas incisas e impresas del Otero (Caracenilla). 


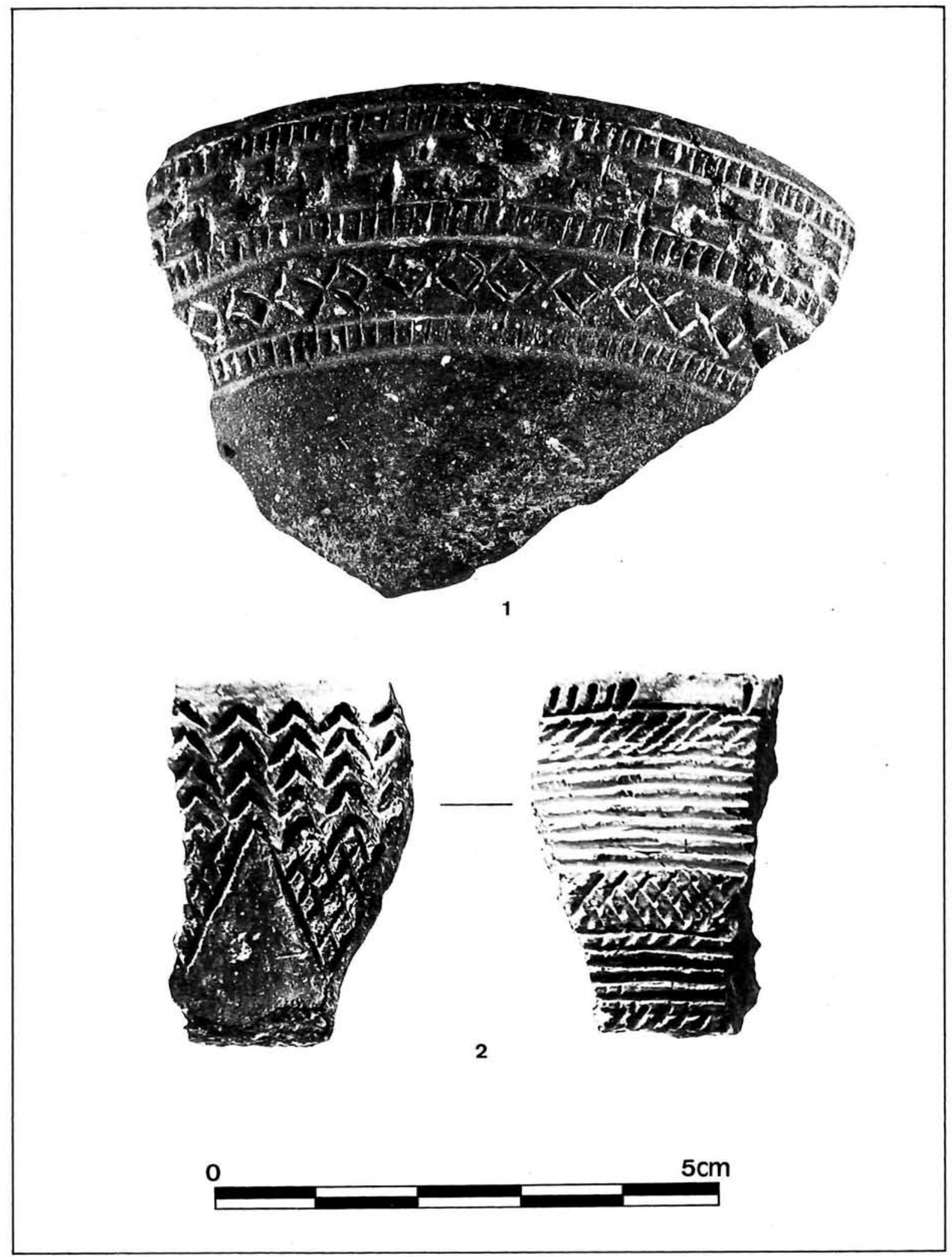

Fragmentos de cuencos. 1) Buendía y 2) Huete. 